\title{
Pin-on-Disc Study of Tribological Performance of PVD Coatings
}

\author{
Mária Hagarová1, Dagmar Jakubéczyová², Martin Fides², Marek Vojtko², Jarmila Savková ${ }^{3}$ \\ ${ }^{1}$ Institute of Materials Science and Quality Engineering, Faculty of Materials, Metallurgy and Recycling, \\ Technical University of Košice, Košice, Slovakia \\ ${ }^{2}$ Institute of Materials Research, Slovak Academy of Science, Košice, Slovakia \\ ${ }^{3}$ The University of West Bohemia in Pilsen, Pilsen, Czech Republic \\ Email: maria.hagarova@tuke.sk,jakubeczy@gmail.com,mfides@saske.sk,mvojtko@saske.sk, savkova@ntc.zcu.cz
}

How to cite this paper: Hagarová, M., Jakubéczyová, D., Fides, M., Vojtko, M. and Savková, J. (2018) Pin-on-Disc Study of Tribological Performance of PVD Coatings. Journal of Surface Engineered Materials and Advanced Technology, 8, 15-25.

https://doi.org/10.4236/jsemat.2018.81002

Received: September 7, 2017

Accepted: January 21, 2018

Published: January 24, 2018

Copyright $\odot 2018$ by authors and Scientific Research Publishing Inc. This work is licensed under the Creative Commons Attribution International License (CC BY 4.0).

http://creativecommons.org/licenses/by/4.0/

\begin{abstract}
This paper deals with the evaluation of tribological properties of PVD coatings which are mainly used as wear resistance coatings. The aim of the work was to compare the tribological behaviour of TiCrN and TiAlCrN coatings deposited on the steel substrate using the technology of reactive cathode vapour deposition. The dry sliding wear of coatings has been investigated against tungsten carbide (WC) counterpart. The course of the friction coefficient indicated better sliding properties $\mathrm{TiAlCrN}$ with value 0.605 compared to $\mathrm{TiCrN}$ with friction coefficient value 0.877 . The depth of worn-out surface amounted to about $2 / 3$ of the worn-out surface of TiCrN coating. The surface of the WC ball showed higher roughening after tribo test of TiCrN.
\end{abstract}

\section{Keywords}

PVD Coatings, Tribological Properties, Wear

\section{Introduction}

Dynamic industrial development places high demands on improvement of properties of materials stressed under operational conditions. This concerns in the first place construction materials and materials for the production of tools and machine parts. High operational reliability and adequate service life are, in the majority of cases, dependent on the quality of parts surfaces [1]. This requirement is important because of the combination of various mechanisms of wear that can result in failure of tools. Complex geometry of tools frequently prevents the use of other methods of treatment besides machining [2] [3]. The service life of tools manufactured from steel for hot use depends on adequate 
execution of thermal processing, suitable operation conditions and the use of a suitable lubricant for the respective cutting tool. Prolongation of service life may be achieved by thermal chemical processing and deposition of coating on the tool surface [4].

Hard coatings are considered a potential way of reducing the degradation effect of friction through ensuring high hardness and chemical stability of the surface [5]. PVD coatings have been widely used also owing to the low temperature of their deposition. In practical life, independent of the way of deposition, the predominant issue is prevention of damage to the surface resulting in unplanned shortening of functionality and service life of the coating [6]. The use of hard PVD coatings cannot always ensure optimum tribological performance; this is frequently limited by elastic and plastic deformation of both the coating and surface, potentially resulting in coating failure [3]. However, hardness is not the only factor that can reduce the coefficient of friction. High temperature and stress that develop at mutual contact of two different materials may change mainly the structure of surfaces, their microgeometry and other properties, which can eventually change the value and course of friction coefficient and the character and extent of wear [7]. Meeting simultaneously all of the satisfactory PVD properties, like high deposition efficiency, good coating substrate adhesion, and no interaction of the coating with the environment, is impossible. In order to obtain a coating with the excellent performances, it is a practical method to design the coatings in three zones: top-layer, interlayer, and a transition layer (a contact diffusion zone with the substrate material) [8].

The real tribological behaviour of materials can be determined only experimentally. Tribological studies of hard coatings are carried out by means of a sliding test [9] [10] [11] [12]. The extent of wear and the course of friction coefficient during the Pin-on-Disc test depend particularly on mechanical and physical properties of a pin and coating materials, the contact surface (given by pin shape and microgeometry of coating surface), surrounding environment, duration of test, relative sliding speed of the ball and specimen surface and the loading force [13]. By measuring the wear track/area and analysing the track surface following the test, one can obtain important information about the wear process and adhesion-cohesion behaviour of the thin layer-substrate system.

\section{Experimental Procedure}

\subsection{Materials}

TiCrN and TiAlCrN coatings were deposited on steel substrate Böhler K110 (DIN X 155CrVMo12-1). It is a high-carbon steel with $1.55 \% \mathrm{C} ; 0.25 \% \mathrm{Si}$; $0.35 \% \mathrm{Mn} ; 11.80 \% \mathrm{Cr} ; 0.80 \% \mathrm{Mo} ; 0.95 \% \mathrm{~V})$ using the technology of reactive cathode vapour deposition (Physical Vapour Deposition PVD).

The steel substrate was thermally treated to the hardness of $63 \mathrm{HRC}$ before coating deposition. Its structure consisted of tempered martensite and carbides. This structure exhibiting high resistance to abrasive wear, good toughness and 
dimensional stability. Prior to a deposition, the surface was cleaned-directly in the coating machine-by argon ion bombardment at a pressure of $10^{3} \mathrm{~Pa}$, associated with an increase in activation energy and heated to the required temperature. Technological conditions of the PVD process are shown in Table 1.

\subsection{Experimental Tests}

\subsubsection{Pin on Disc Test}

The Pin-on-Disc test was carried out employing a CSM tribometer under oxidation atmosphere at $20^{\circ} \mathrm{C}-22^{\circ} \mathrm{C}$ (room temperature). As a counterpart (pin) we used a ball from sintered carbides based on wolfram WC-Co. Conditions of the tribo test are shown in Table 2.

In addition to friction coefficient $\mu$, we evaluated also a ball track, its width and depth on the surface of the tested coatings and wear of the ball surface following the Pin-on-Disc test.

The mean through the cross-section area was calculated and subsequently the volume of the removed material was estimated. The specific wear rate $(w)$ was then expressed according to the standard ISO 20808:2016 [14], as the volume loss $V\left(\mathrm{~mm}^{3}\right)$ per distance $L(\mathrm{~m})$ and the applied load $F_{p}(\mathrm{~N})$ :

$$
w=\frac{V}{L \cdot F_{p}}
$$

and was used for comparison purposes [15].

\subsubsection{Microscopic Analysis}

The character of the surface after the war was analysed by a confocal microscope

Table 1. Technological parameters of PVD process.

\begin{tabular}{cccccc}
\hline & \multicolumn{5}{c}{ Technological parameters } \\
\cline { 2 - 6 } Coating & Substrate & $\begin{array}{c}\text { Substrate } \\
\text { temperature } \\
\left({ }^{\circ} \mathrm{C}\right)\end{array}$ & $\begin{array}{c}\text { Cathode } \\
\text { current (A) }\end{array}$ & $\begin{array}{c}\text { Substrate } \\
\text { bias }(\mathrm{V})\end{array}$ & $\begin{array}{c}\text { Pressure } \\
(\mathrm{Pa})\end{array}$ \\
\hline \multirow{2}{*}{ TiCrN } & DIN X & 350 & $\mathrm{Ti} / 50$ & $100-300$ & 2.0 \\
& $155 \mathrm{CrVMo}$ & & $\mathrm{Cr} / 50$ & & \\
TiAlCrN & $12-1$ & 450 & $\mathrm{TiAl} / 80$ & $200-300$ & 4.0 \\
\hline
\end{tabular}

Table 2. Tribo test conditions.

\begin{tabular}{cc}
\hline Parameter & Value \\
\hline Sliding speed $(\mathrm{m} / \mathrm{s})$ & 0.04 \\
Track length $(\mathrm{m})$ & 500.00 \\
Load force $(\mathrm{N})$ & 5.00 \\
Track radius $(\mathrm{mm})$ & 2.00 \\
Temperature $\left({ }^{\circ} \mathrm{C}\right)$ & $20 \pm 2$ \\
$\phi$ Ball WC/Co $(\mathrm{mm})$ & 6.00 \\
Test duration $(\mathrm{min})$ & $\sim 208$ \\
\hline
\end{tabular}


Pluneox of company Sensofar. Confocal microscopy allows volume scanning of microstructures by selectively displaying parallel sections [16].

\section{Results and Discussion}

Figure 1 shows the course of friction coefficient $\mu$ of $\operatorname{TiCrN}$ coating after wear produced by WC ball during tribotest. The friction coefficient increased steadily without pronounced dispersion up to approximately $900 \mathrm{sec}$, when it reached approx. 0.7. After this time, it increased slowly to the maximum of $\mu \sim 0.877$, reached after 12,000 sec of testing. The mean value of friction coefficient was 0.777. The small variations in its course were related to microgeometry on the coating surface.

Figure 2 shows the course of friction coefficient of TiAlCrN coating following the tribo test. Within the first $2000 \mathrm{sec}$. of testing, the friction coefficient reached the maximum value of $\mu=0.746$. Next which motion of the pin for $6000 \mathrm{sec}$. were observed and the value of the coefficient $\mu$ decrease and stabilized at $\mu \sim 0.6$ which persisted up to termination of the test. The mean value of friction coefficient of the coating had value 0.605 . In the first stage of testing (up to approx. 3000 seconds), the friction coefficient $\mu$ showed greater variation ( $\max \mu=$ 0.746 ) that could be explained by the presence of oxidized layer and unevenness

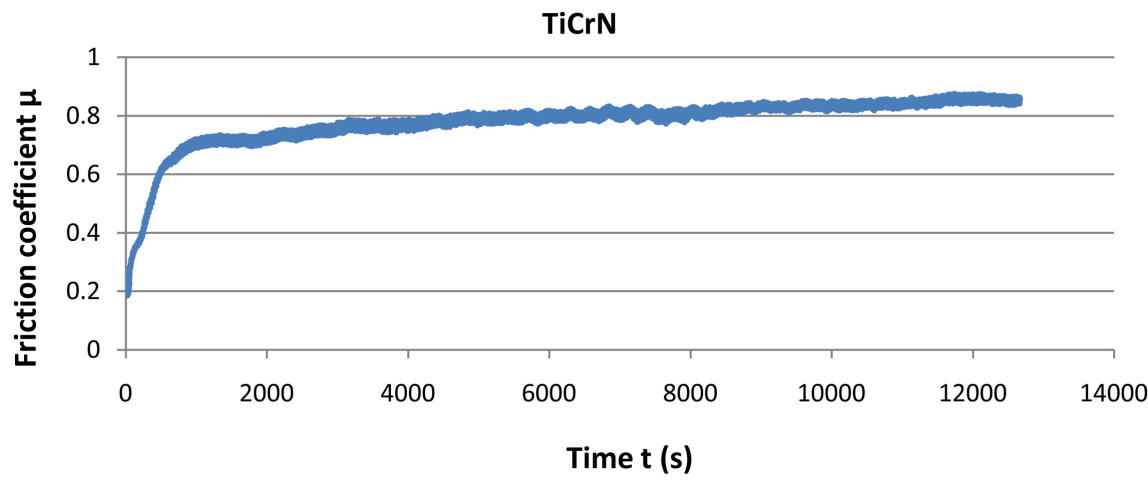

Figure 1. The course of friction coefficient of TiCrN coating following the Pin-on-Disc test.

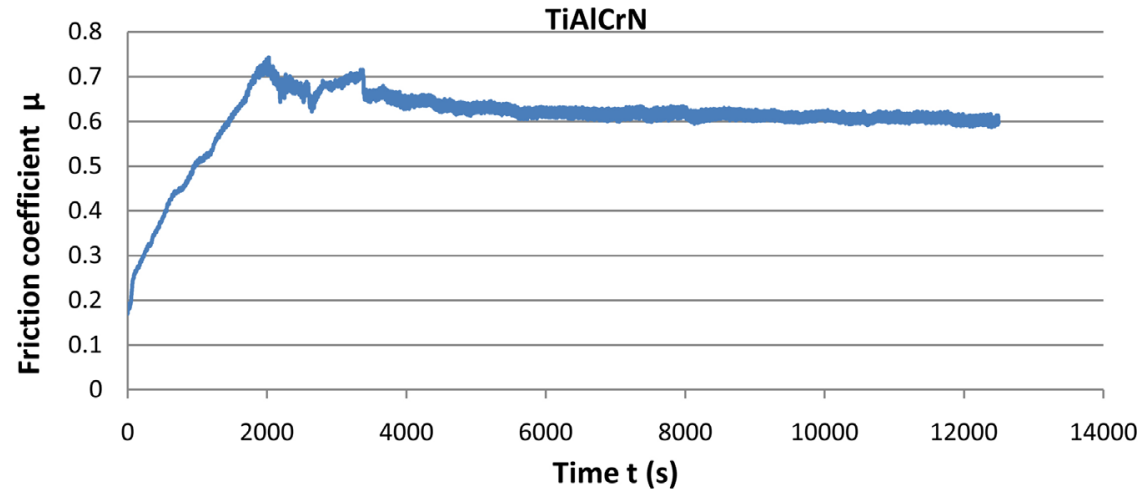

Figure 2. The course of friction coefficient of TiAlCrN coating following the Pin-on-Disc test. 
of coating surface.

Figure 3 shows a 3D picture of tribo wear track following the Pin-on-Disc test on TiCrN coating after track length of $500 \mathrm{~m}$ produced by a WC ball. The scheme of this wear track with a maximum depth of wear equal to $0.34 \mu \mathrm{m}$ and relevant area is presented in Figure 4. The Figure 3 and Figure 4 show that the greatest failure of coating occurred in the centre of wear track and the coating material accumulated on both sides sometimes to the height of $0.35 \mu \mathrm{m}$. This was due to the shift of surface coating material from the centre to the sides of the track, which is a coincident characteristic of the Pin-on-Disc test.

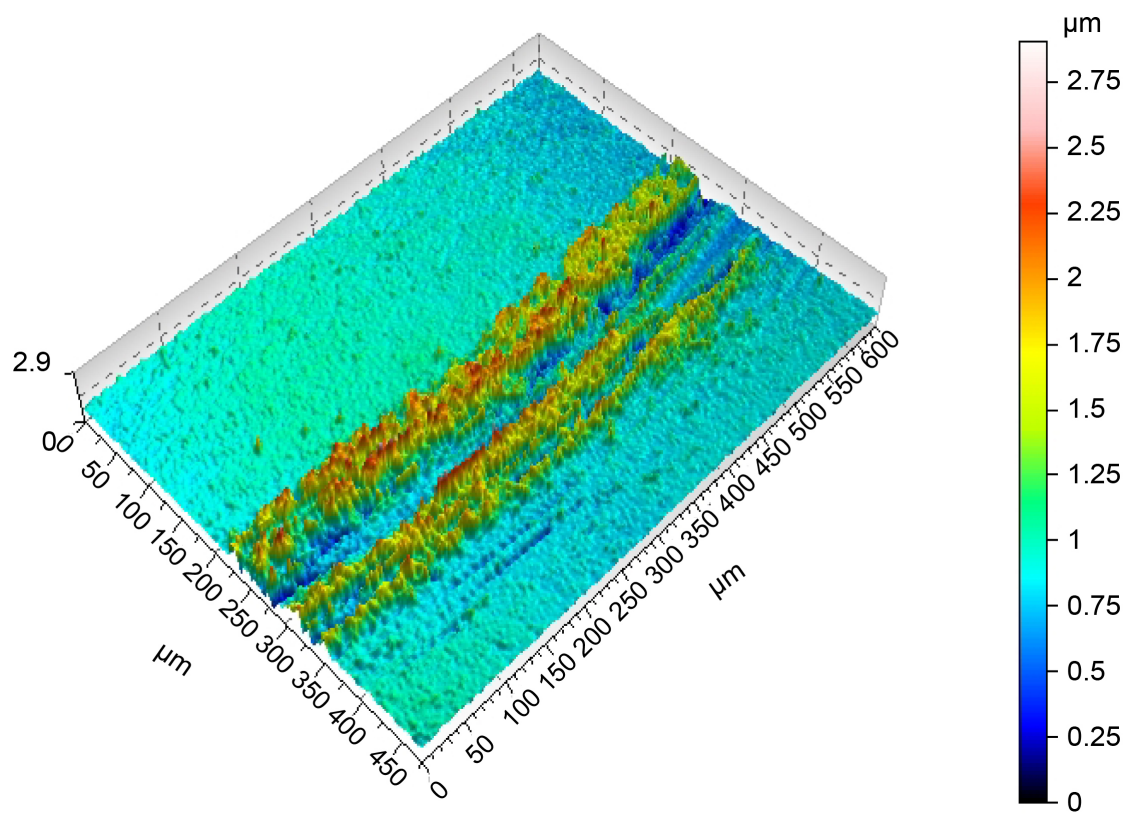

Figure 3. 3D picture of the tribo wear track on $\mathrm{TiCrN}$ coating produced during the Pin-on-Disc test.

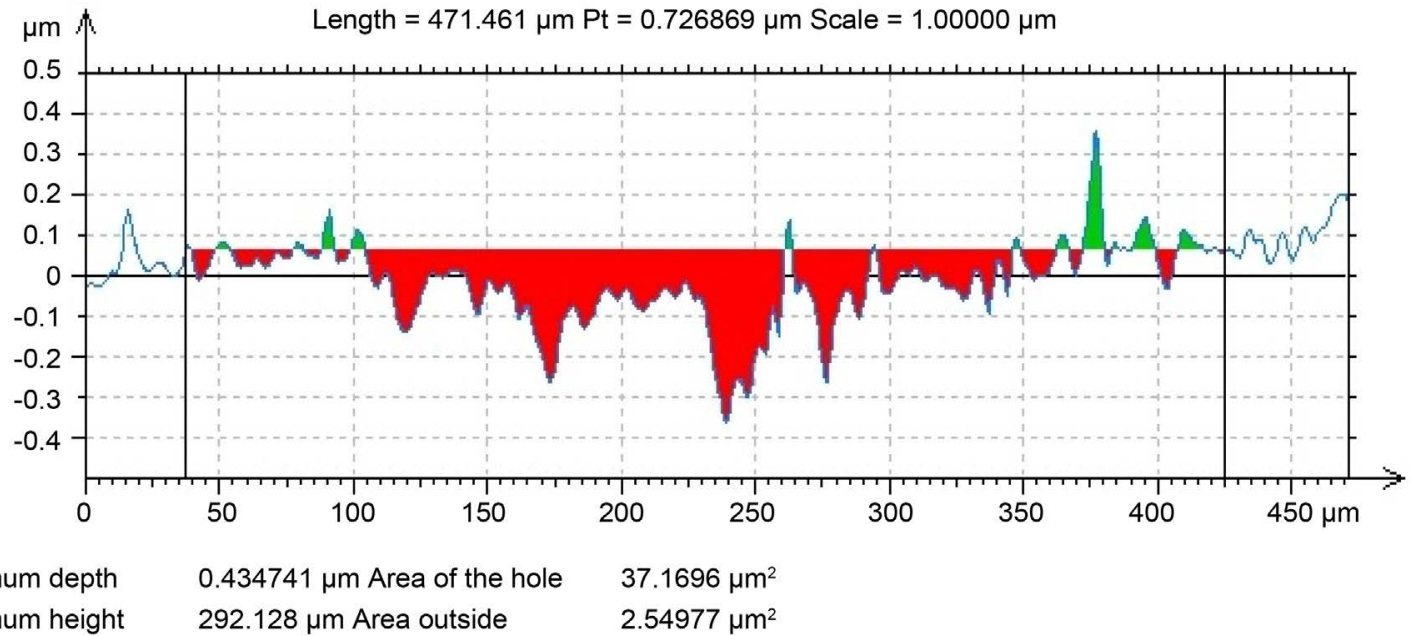

Figure 4. Scheme of the tribo wear track on TiCrN coating produced by the Pin-on-Disc with a maximum depth of wear of $0.35 \mu \mathrm{m}$. 
The maximum depth of wear $(0.35 \mu \mathrm{m})$ after the tribo test shown in Figure 4 allows one to conclude that in the case of $\mathrm{TiCrN}$, the coating was not re-ground always down to the substrate, as the coating depth was as high as $1.047 \mu \mathrm{m}$ (see Figure 5(a)). Figure 5(b) documents linescan analysis of elements across the TiCrN coating by REM up to a depth $3 \mu \mathrm{m}$.

The character of wear of the TiAlCrN coating after the tribo test is shown in

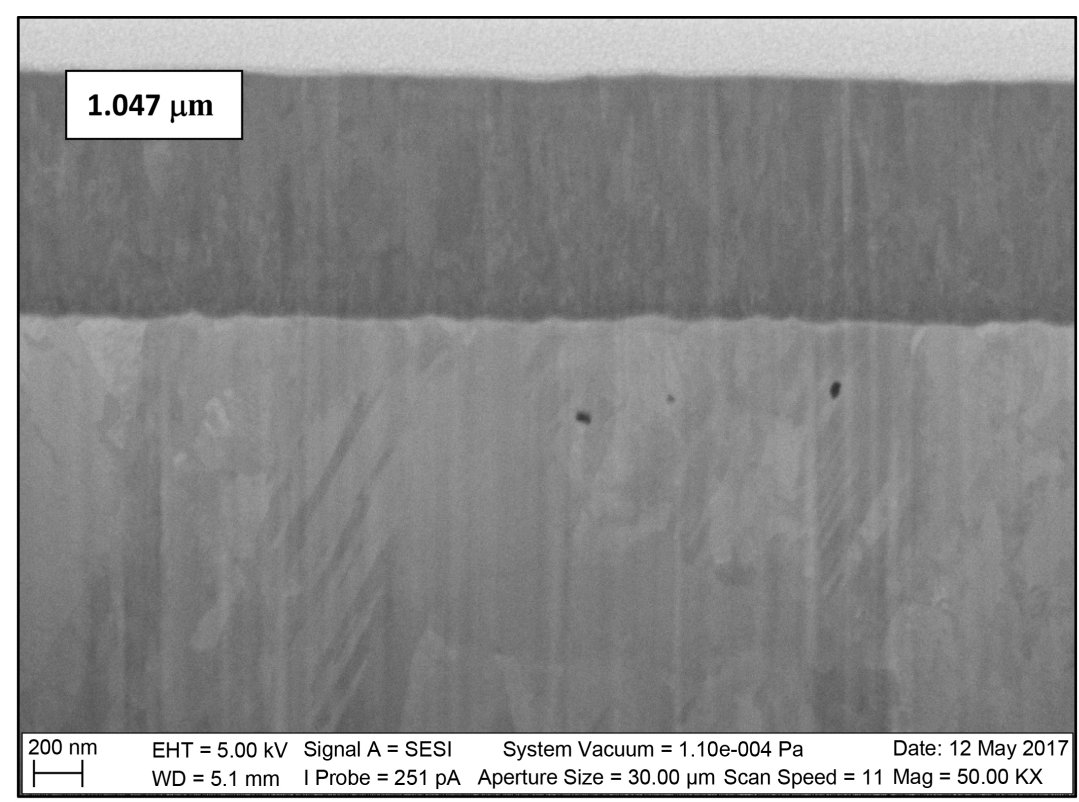

(a)
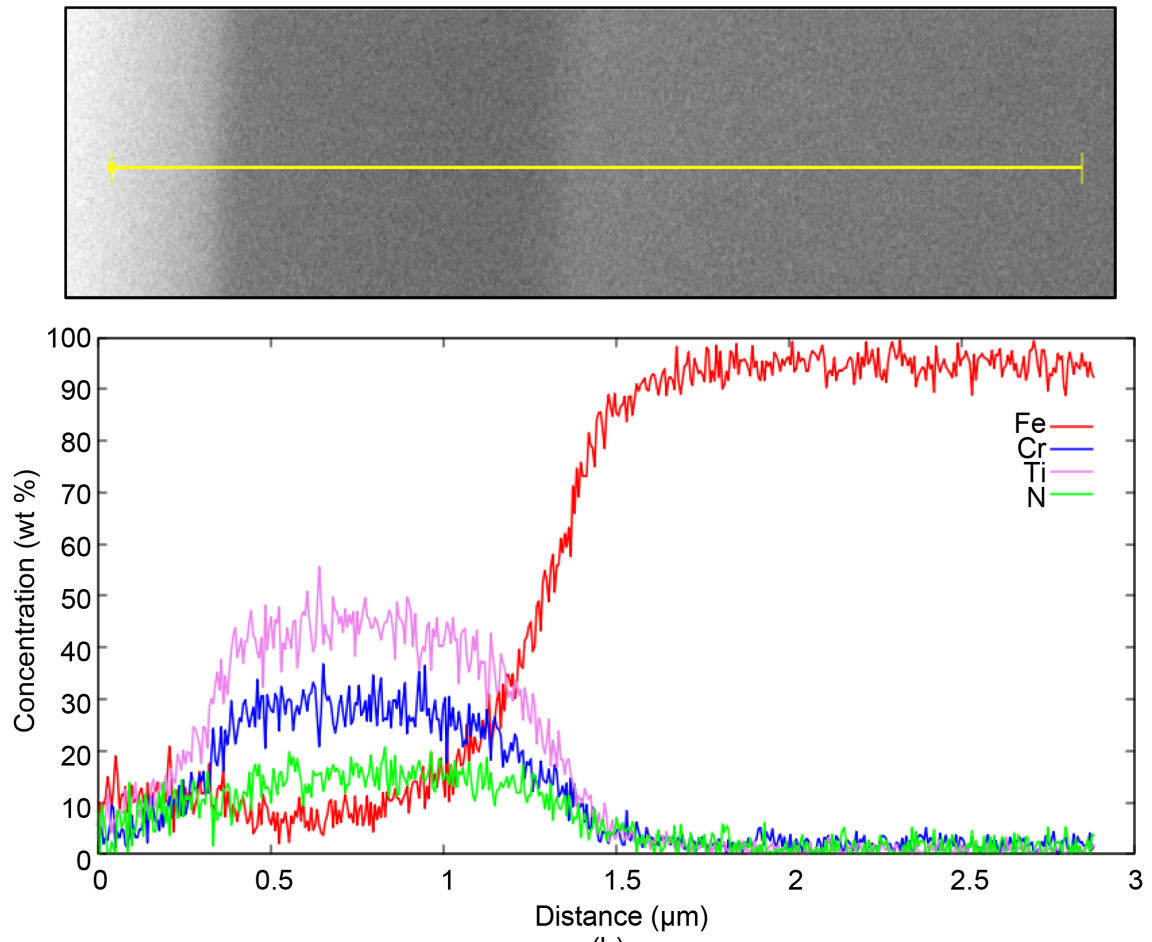

(b)

Figure 5. (a) Cross-section of the TiCrN coating, REM-FIB; (b) Linescan Analysis of the elements across the thickness of the TiCrN coating, REM-FIB. 
Figure 6 and Figure 7. The comparison of the surface of the TiCrN coating (see Figure 3) with that of TiAlCrN surface (see Figure 6) indicated that the wear track of the latter was by far shallower and smoother and the shift of the coating material from the centre to the sides of the wear track was less pronounced.

It was observed again that even after $500 \mathrm{~m}$ of action of the WC ball no re-grinding down to the substrate surface occurred. The maximum depth of wear of the coating of thickness $1.146 \mu \mathrm{m}$ was $100-137 \mathrm{~nm}$, Figure 8(a)). Figure 8 (b) illustrates linescan analysis of elements across the TiAlCrN coating by REM up to a depth $3 \mu \mathrm{m}$.

Comparison of wear tracks after $500 \mathrm{~m}$ wear length showed greater wear of

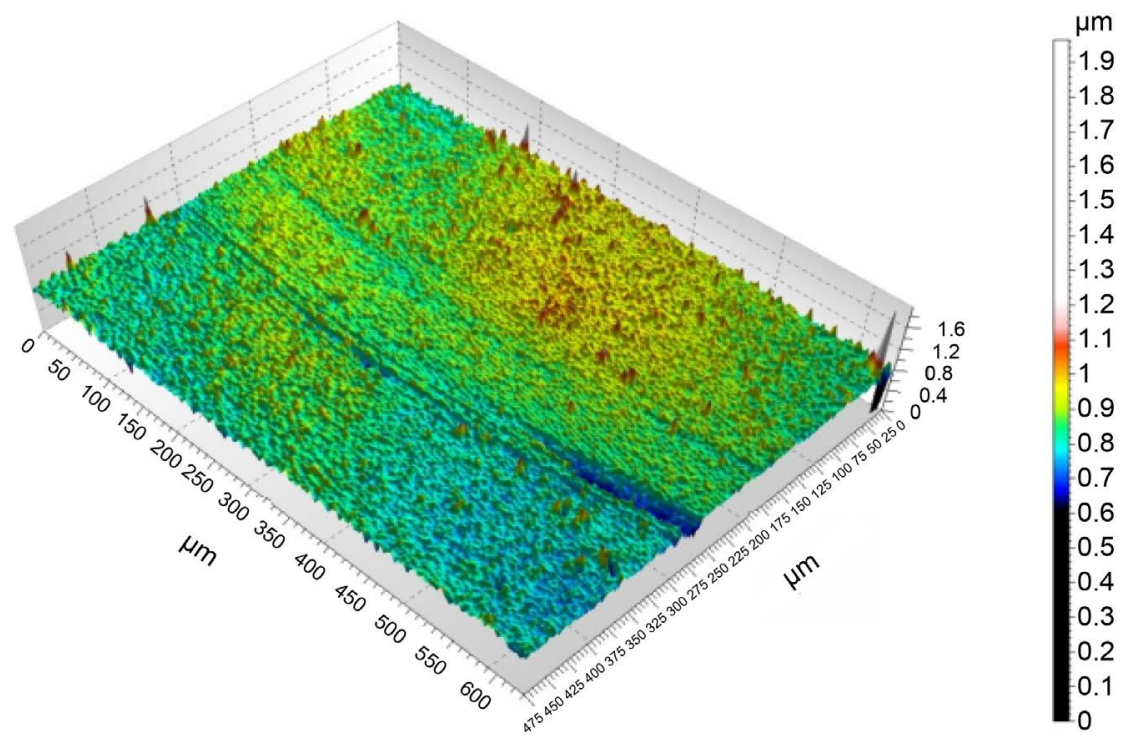

Figure 6. 3D picture of the tribo wear track on TiAlCrN coating produced by the Pin-on-Disc test.

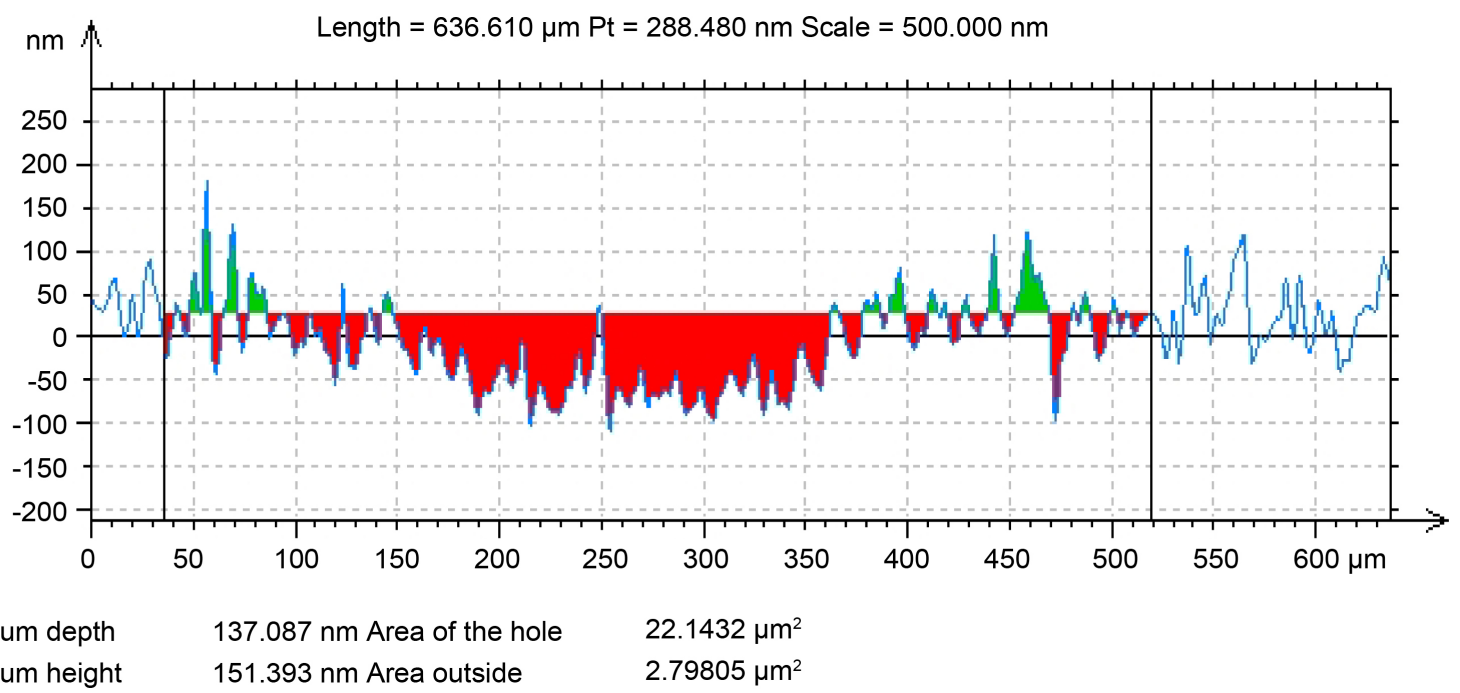

Maximum depth Maximum height
$137.087 \mathrm{~nm}$ Area of the hole $151.393 \mathrm{~nm}$ Area outside
$22.1432 \mu \mathrm{m}^{2}$

Figure 7. Scheme of the tribo wear track on TiAlCrN coating produced by the Pin-on-Disc test with a maximum depth of wear $0.1 \mu \mathrm{m}$. 


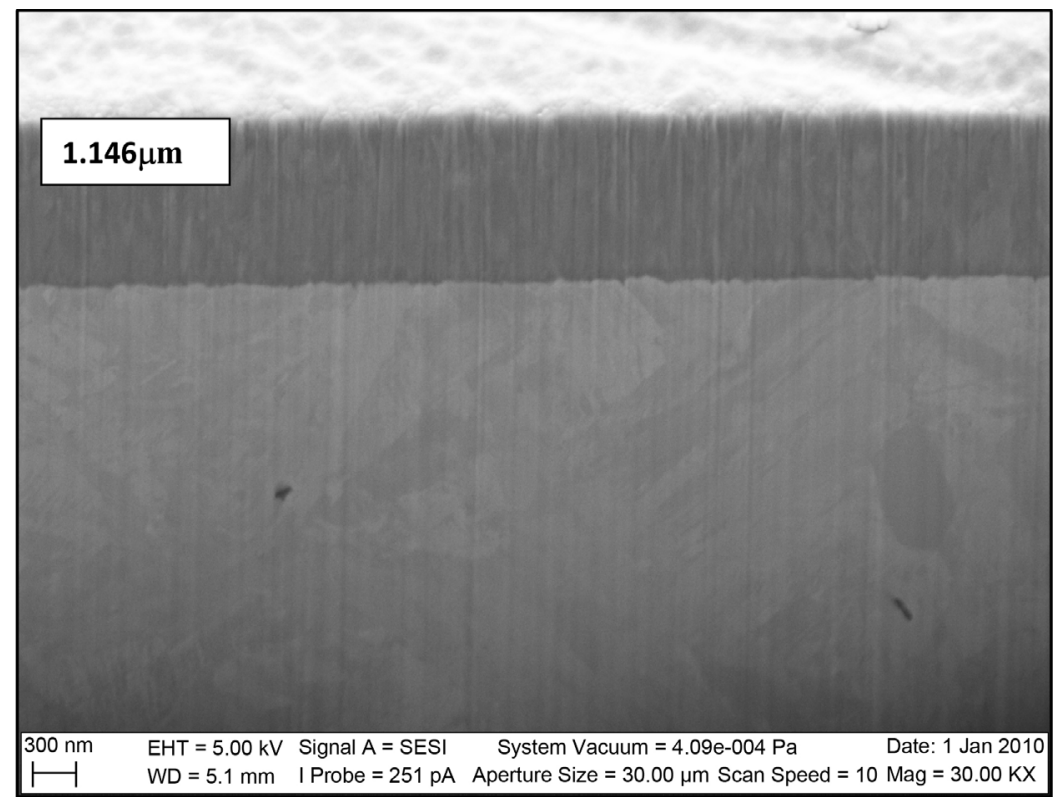

(a)

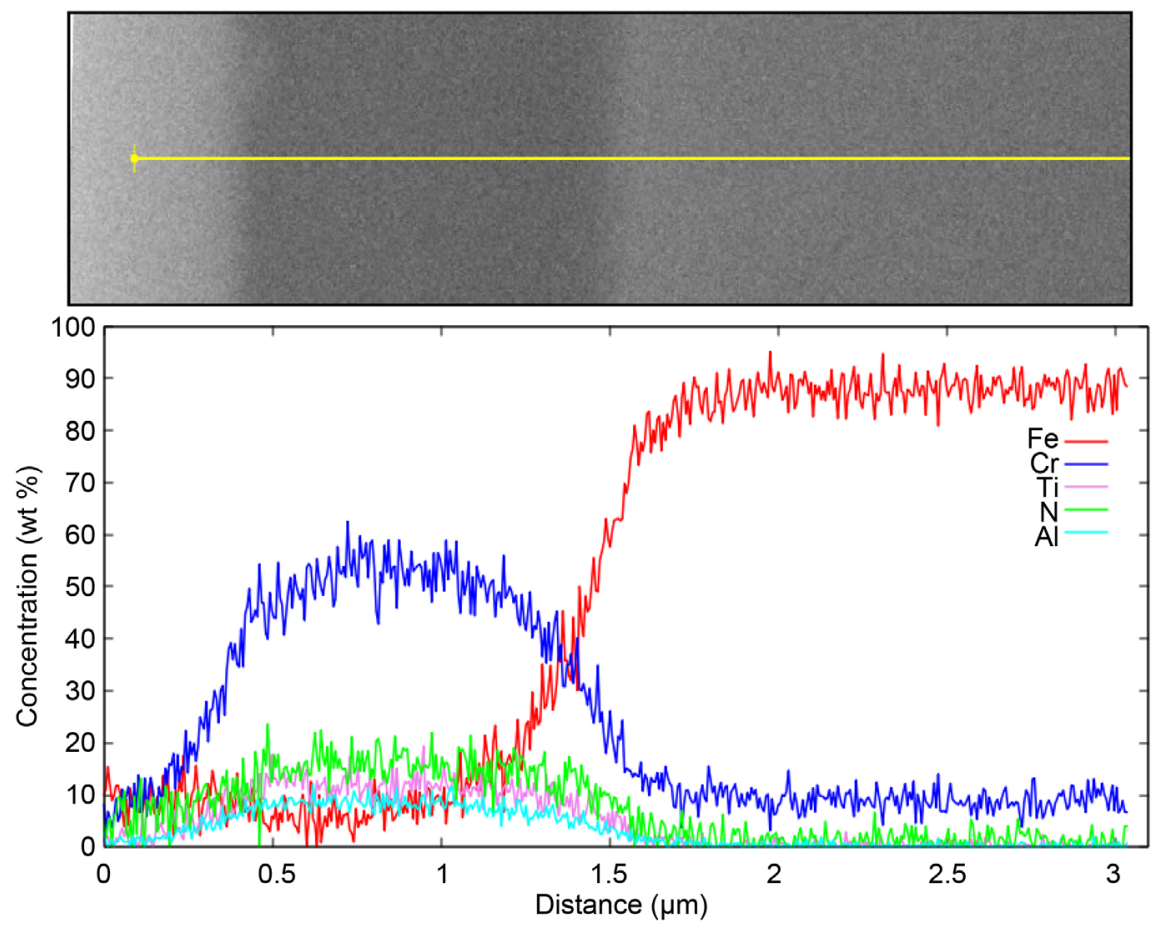

(b)

Figure 8. (a) Cross-section of coating TiAlCrN, REM-FIB; (b) Linescan analysis of the elements across the thickness of the TiAlCrN coating, REM-FIB.

the TiCrN coating (Figure 3 and Figure 4). On both wear scar sides there was a considerable accumulation of coating material due its shifting from centre of track to its sides. In this case, both the depth of wear and track width were greater.

Results of adhesion-cohesion behaviour of the coated system are summarised in Table 3, providing results of friction coefficients, width and depth of wear 
tracks, area of wear track profile and microhardness of coating at $0.5 \mathrm{~N}$ loading. One can observe a correlation with regard to hardness: the TiAlCrN coating exhibited higher resistance to wear. The latter coating showed lower friction coefficient, depth of wear track and the area of wear track profile.

Figure 9 to Figure 10 show the worn-out surface of WC balls after tribotest of PVD coatings. It is evident that the roughening of WC ball surface used for testing of TiCrN coating (see Figure 10) is greater primarily due to sticking of the coating to ball surface.

Table 3. Results of Pin-on-Disc test of the studied PVD coatings.

\begin{tabular}{cccccc}
\hline Coating & $\begin{array}{c}\text { Mean value } \\
\text { of friction } \\
\text { coefficient }\end{array}$ & $\begin{array}{c}\text { Maximum } \\
\text { value of } \\
\text { friction } \\
\text { coefficient }\end{array}$ & $\begin{array}{c}\text { Max. track } \\
\text { depth } \\
(\mu \mathrm{m})\end{array}$ & $\begin{array}{c}\text { Area of wear } \\
\text { track profile } \\
\text { height/depth } \\
\left(\mu \mathrm{m}^{2}\right)\end{array}$ & $\begin{array}{c}\text { HVm } \\
(\mathbf{0 . 5})\end{array}$ \\
\hline TiNCrN & 0.777 & 0.877 & 0.35 & $2.549 / 37.169$ & $761.9 \pm 107.2$ \\
TiAlCrN & 0.605 & 0.746 & 0.10 & $2.798 / 22.143$ & $1358.0 \pm 149.9$ \\
\hline
\end{tabular}

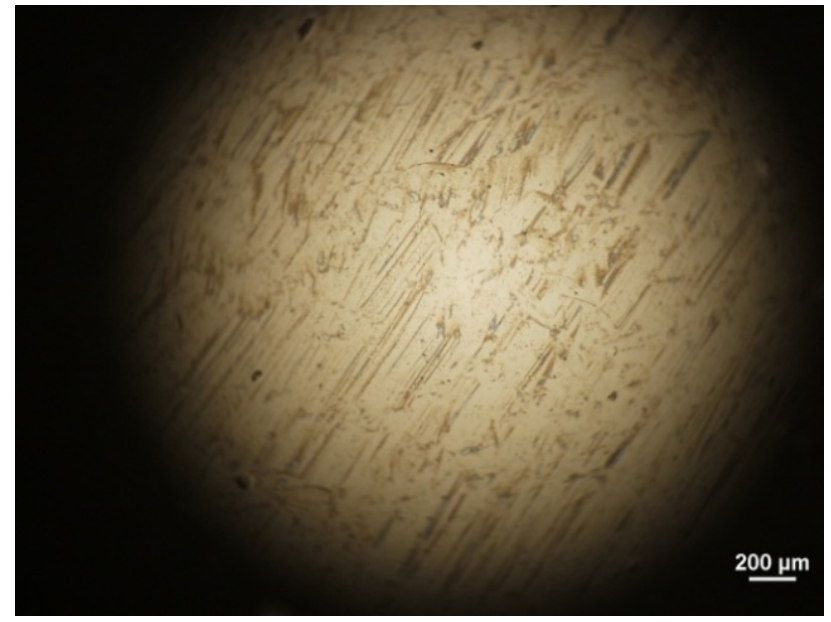

Figure 9. Wear of the WC ball after tribotest of TiCrN coating.

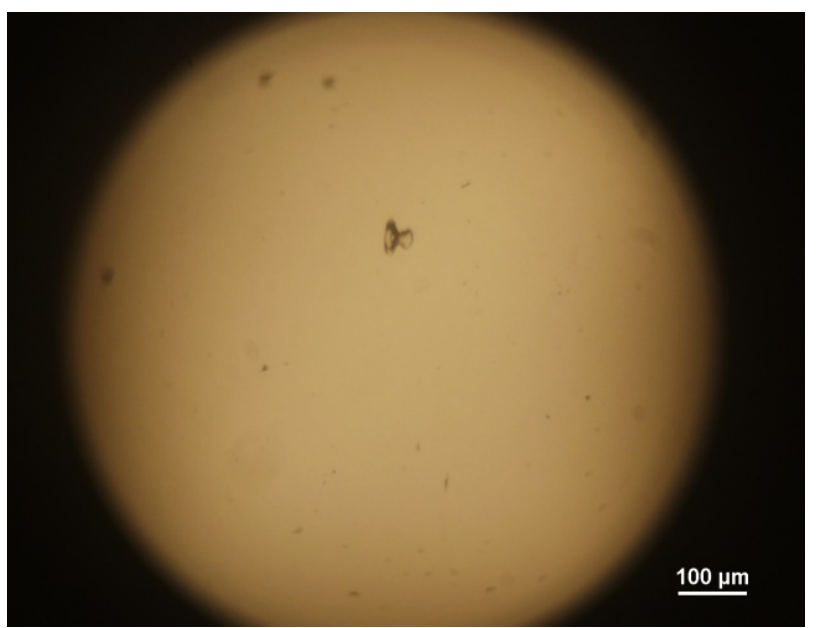

Figure 10. Wear of the WC ball after tribotest of TiAlCrN. 


\section{Conclusions}

Tribotest of thin TiCrN and TiAlCrN PVD coatings, deposited on steel substrate allowed us to carry out a preliminary assessment of adhesion-cohesion behaviour of the coated systems:

1) The course of the friction coefficient indicated better sliding properties TiAlCrN with value 0.605 compared to $\mathrm{TiCrN}$ with friction coefficient value 0.877 .

2) The wear of TiAlCrN coating was lower. The depth of worn-out surface amounted to about $2 / 3$ of the worn-out surface of TiCrNN coating,

3) The depth of TiAlCrN coating wear track was lower by $0.25 \mu \mathrm{m}$ compared to that of TiCrN coating.

4) No re-grinding down to the steel surface occurred during tribo testing of both investigated coatings,

5) The surface of the WC ball used to show higher roughening after testing the TiCrN coating due to sticking of coating material to ball surface.

More detailed analysis of adhesion-cohesion properties of coated systems could be accomplished by testing the investigated coatings using various pin bodies (as counterparts).

Analysis of the extent of wear of investigated coatings allows one to evaluate the quality of the deposited coatings and on the basis of their properties to specify their use under operational conditions.

\section{Acknowledgements}

The study was carried out within the framework of the national project VEGA 2/0070/17 and APVV-14-0834.

\section{References}

[1] Polok-Rubiniec, M., Dobrzanski, L.A. and Adamiak, M. (2008) The Properties and Wear Resistance of the CrN PVD Coatings. Journal of Achievements in Materials and Manufacturing Engineering, 2, 165-171.

[2] Clarysse, F., Lauwerens, W. and Vermeulen, M. (2008) Tribological Properties of PVD Tool Coatings in Forming Operations of Steel Sheet. Wear, 264, 400-404. https://doi.org/10.1016/j.wear.2006.08.031

[3] Sokovic, M., Panjan, P. and Kirn, R. (2004) Possibilities of Improvement of Dies Casting Tools with Duplex Treatment. Journal of Materials Processing Technology, 157-158, 613-616. https://doi.org/10.1016/j.jmatprotec.2004.07.145

[4] Rodriguez-Baracaldo, R., Benito, J.A., Puchi-Cabrera, E.S. and Staia, M.H. (2007) High Temperature Wear Resistance of (Ti,Al)N PVD Coating on Untreated and Gas Nitrided AISI H13 Steel with Different Heat Treatments. Wear, 262, 380-389. https://doi.org/10.1016/j.wear.2006.06.010

[5] Fu, Y., Wei, J. and Batchelor, A.W. (2000) Some Considerations on the Mitigation of Fretting Damage by Application of Surface Modification Technologies. Journal of Materials Processing Technology, 99, 231-245. https://doi.org/10.1016/S0924-0136(99)00429-X

[6] Liskiewicz, T. and Fouvry, S. (2005) Development of a Friction Energy Capacity 
Approach to Predict the Surface Coating Endurance under Complex Oscillating Sliding Conditions. Tribology International, 38, 69-79.

https://doi.org/10.1016/j.triboint.2004.06.002

[7] Warcholinski, B., Gilewicz, A. and Myslinski, P. (2009) Tribological Properties of TiAlCrN Thin Films. A Review. Advanced Materials Science, 22, 81-88.

[8] Xu, Y., Miao, Q., Liang, W.P., Yu, X.S., Jiang, Q., Zhang, Z.G., Ren, B.L. and Yao, Z.J. (2015) Tribological Behavior of $\mathrm{Al}_{2} \mathrm{O}_{3} / \mathrm{Al}$ Composite Coating on $\gamma$-TiAl at Elevated Temperature. Materials Characterisation, 101, 122-129. https://doi.org/10.1016/j.matchar.2015.01.009

[9] Holmberg, K., Ronkainen, H. and Matthews, A. (2000) Tribology of Thin Coatings. Ceramics International, 26, 787-795.

https://doi.org/10.1016/S0272-8842(00)00015-8

[10] Holmberg, K., Mathews, A. and Ronkainen, H. (1998) Coatings Tribology-Contact Mechanisms and Surface Design. Tribology International, 31, 107-120. https://doi.org/10.1016/S0301-679X(98)00013-9

[11] Holmberg, K. and Mathews, A. (1994) Coatings Tribology; Properties, Techniques and Applications in Surface Engineering. Elsevier Science B.V., Amsterdam.

[12] Hedenquist, P., Jacoson, S. and Hogmark, S. (1997) Tribological Laboratory Evaluation of Thin Hard Coatings. Surface and Coatings Technology, 97, 656-660. https://doi.org/10.1016/S0257-8972(97)00333-2

[13] Bruce, W. (2012) Handbook of Lubrication and Tribology, Volume II: Theory and Design. 2nd Edition, Taylor \& Francis Group, Abingdon.

[14] https://www.iso.org/standard/65415.html

[15] Jakubéczyová, D. and Ballóková, B. (2014) Analysis of Tribological Properties of Multi- and Nanocomposite Coatings Deposited on a PM Substrate. Powder Metallurgy Progress, 1, 46-51.

[16] Balko, J., Ballóková, B., Jakubéczyová, D., Hvizdoš, P., Hloch, S., Kloc, J. and Monka, P. (2013) Wear and Mechanical Behaviour of Various Poly(methyl methacrylate) Bone Cements. Powder Metallurgy Progress, 1, 34-43. 